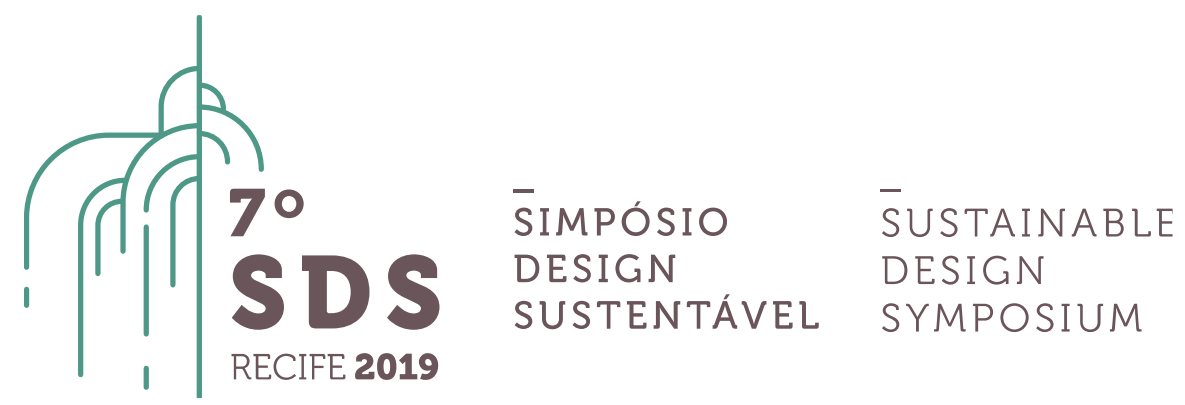

\title{
O Efeito Borboleta de Bistagnino: Notas Críticas ao Design Sistêmico
}

\author{
Ana Paula Silveira dos Santos ${ }^{1}$, Douglas Onzi Pastori ${ }^{2}$, Rodrigo Najar ${ }^{3}$ \\ ${ }^{1}$ Unisinos, PPG Design, anapsilveira@edu.unisinos.br \\ 2 Unisinos, PPG Design, dopastor@ucs.br \\ ${ }^{3}$ Unisinos, Departmento, PPG Design, najjar.rodrigo@gmail.com
}

\begin{abstract}
Resumo. $O$ presente artigo pretende investigar criticamente pontos considerados relevantes da teoria e do método do Design Sistêmico do professor italiano Luigi Bistagnino a partir da experiência de um workshop projetual com estudo de caso aplicado sobre o ecossistema criativo Vila Flores de Porto Alegre. Sua inflexão se dá principalmente sobre a insuficiência metodológica do Design Sistêmico em dar conta da complexidade do componente humano atuante em sistemas sociais abertos, dinâmicos, vivos, e portanto, dos produtos materiais e imateriais que caracterizam a semiosfera e a noosfera humana, comprometendo parcialmente a positividade dos resultados projetuais desta metodologia de design orientada para a sustentabilidade.
\end{abstract}

Palavras-chave. Design Sistêmico, Pensamento Sistêmico, Sustentabilidade, Ecologia Humana, Ecossistema Criativo, Vila Flores.

\section{Introdução}

O efeito borboleta é um conceito da Teoria do Caos que tenta afirmar que fenômenos quase incomensuráveis podem influenciar na realização de uma série de acontecimentos estatisticamente previsíveis, tornando-os imprevisíveis caso não sejam levados em conta.

Isto diz muito sobre os modos de análise de sistemas complexos, dinâmicos, longe do equilíbrio, que são também os sistemas que o Design Sistêmico tenta dar conta com soluções projetuais. Nesse sentido, a gravata borboleta do professor Bistagnino não só serve de metáfora ou recurso retórico, mas como imagem alegórica com poder heurístico para sinalizar que acontecimentos mínimos podem determinar o curso do futuro. Portanto, um mero workshop projetual, dos inúmeros já ocorridos e orientados pelo professor Bistagnino, pode servir de insumo para a reflexão crítica do seu método e da sua teoria de design e assim reorientar o seu próprio destino.

Neste artigo, parte-se de uma revisão rápida da teoria e do método do Design Sistêmico para aprofundar atenção na prática projetual permitida pelo workshop de Design Sistêmico, esse oferecido pelo programa de pós-graduação em Design da Universidade do Vale do Rio dos Sinos 
em parceria com o programa de pós-graduação em Design da Universidade Estadual de Minas Gerais, tendo como tema a economia criativa do Distrito $\mathrm{C}$ de Porto Alegre e como estudo de caso o ecossistema criativo Vila Flores.

O objetivo é levantar algumas questões consideradas relevantes a partir de uma perspectiva epistemológica e metodológica crítica, tensionando o Design Sistêmico para novos direcionamentos teóricos e projetuais que se insinuam na parte final do artigo. Ressalta-se neste artigo, a importância do Design Sistêmico para a viabilização de alternativas de um mundo mais sustentável para as formas de vida humanas e não-humanas e a permanente necessidade de reflexão crítica e aperfeiçoamento metodológico a fim de garantir respostas à altura das demandas levantadas.

\title{
2 O Design Sistêmico: teoria e método
}

O Design Sistêmico foi desenvolvido pelo professor italiano do Politécnico de Torino, Luigi Bistagnino, como uma metodologia que representa uma alternativa aos modelos vigentes de atividades de design e parte do princípio de que os problemas de projeto atuais são sistêmicos e imersos em relações de interdependência. Pretendendo uma ruptura paradigmática ao design centrado na mercadoria e no consumidor, Bistagnino (2008) destaca a necessidade de uma retomada da centralidade do humano não só nas atividades projetuais, mas como ponto focal das tramas complexas, por vezes caóticas, das soluções projetuais as quais o design advindo da tradição industrial, legou para a contemporaneidade. Na proposta de Bistagnino (2008), portanto, há a pretensão de não reduzir o humano a um conjunto de fatores instrumentalizáveis e quantificáveis típico da abordagem humanista do funcionalismo, mas capaz de conectar a multifatoriedade e assumí-la de acordo com a complexidade de uma vida biológica, social, ética e cultural.

\begin{abstract}
"A questão é aquela de captar em ato a diversidade na qual se desenvolve a vida de milhões de pessoas (cada uma desdobrada em contextos sociais, éticos e culturais tanto disformes quanto únicos), para então poder agir produtivamente de modo concentrado e não confundindo as várias utilidades como se compusessem uma única dimensão sem distinções, privada de vontades peculiares e caracterizada somente de necessidades contingentes e desejos indiferenciados.
\end{abstract}

É como se a vida, hoje, fosse escrava de objetos inanimados, quando na realidade o oposto deveria acontecer; os produtos devem ser simplesmente os meios essenciais através dos quais o ser humano expressa as ações que permitem sua existência". (BISTAGNINO, 2008: 16). ${ }^{1}$

O professor italiano, mesmo fazendo uso de uma operacionalidade de natureza sistêmica, não abre mão do existencialismo humanista para fundamentação do seu método. Nele fica evidente que a análise sistêmica não faz sentido se não for ancorada em valores que privilegiem o componente humano em todo o seu sentido. Pois se foi pelo humano que a atual situação de degradação ambiental, social e ética se tornou possível, é somente com ele que se poderá criar outras situações que permitam que novas possibilidades de futuro sejam destinadas, do contrário,

\footnotetext{
1 "La questione è quella di prendere atto delle diversità in cui si svolge la vita di milioni di persone (ciascuna calata in contesti sociali, etici e culturali tanto difformi quanto unici), così da poter agire produttivamente in modo mirato e non confondendo le varie utenze come se appartenessero a un unicum indistinto, privo di una volontà peculiare e caratterizzato solo da necessità contingenti e da bisogni indifferenziati. È come se la vita, oggi, fosse schiava di oggetti inanimati, quando in realtà dovrebbe avvenire il contrario; i prodotti dovrebbero semplicemente essere i mezzi essenziali attraverso i quali l'essere umano esprime le azioni che ne consentono l'esistenza." (BISTAGNINO, 2008: 16).
} 
o horizonte da fatalidade do fim do humano já se avista como uma linha que, quanto mais próxima, mais incontornável ela se torna. Ou seja, é a partir de uma situação de crise que se origina o Design Sistêmico e nela se consolida como crítica construtiva, pretendendo-lhe viabilizar saídas eficazes em tempo hábil.

Os objetivos desta metodologia estão primordialmente ligados ao desenvolvimento de artefatos sustentáveis, pessoas saudáveis e um meio-ambiente equilibrado. Seu foco desloca-se dos produtos para os processos e a lógica do atual mercado, pautada unicamente por demandas econômicas, estruturada em processos mecanicistas e lineares. Nesse sentido, Bistagnino propõe uma perspectiva transvalorativa, com a intenção de considerar valores outros, como a sustentabilidade dos modelos sociais e o equilíbrio dos sistemas econômicos em relação aos ecológicos. Segundo Bistagnino (2011), os processos praticados pelo modelo globalizado de economia dominante produzem - por sua própria natureza e pelos valores que propagam - uma enorme quantidade de resíduos, "É como se a vida, hoje, fosse escrava de objetos inanimados, quando na realidade deveria ser o contrário; os produtos deveriam simplesmente ser os meios essenciais pelos quais o ser humano exprime as ações que the dão a existência". (BISTAGNINO, 2008: 16, tradução nossa).

O pensamento e os processos adotados pelo design sistêmico tendem a configurar sistemas abertos em que os outputs de determinada atividade tornem-se inputs de outra pertencente ao mesmo sistema de maneira que haja uma drástica redução nos resíduos produzidos. Mais do que produtos, o design sistêmico propõe-se a projetar sistemas em que as relações entre produção, ambiente e sociedade possam ser reequilibradas, tornando-se mais justas e sustentáveis por longos períodos de tempo. Esta metodologia considera como partes fundamentais do processo as particularidades humanas, culturais, sociais e naturais próprias do território e projeta novas relações entre elas. Os produtos serão consequências destas relações e sistemas e terão uma razão, que não apenas as exigências de uma economia baseada no consumo para existir. Assim, o design sistêmico busca configurar novos modelos econômicos e de produção.

Kátia Pêgo, designer e pesquisadora mineira orientada em doutorado pelo professor Bistagnino, ressalta que, pela ótica do design sistêmico, quando o ser humano está envolvido em um sistema de produção - e sempre está - não se pode pressupor que este se encaixa em um modelo mecanicista e linear agindo como se fosse uma máquina. Segundo a autora, há que se considerar a complexidade das relações humanas e as influências que este exerce sobre a cultura e vice-versa. O ser humano é, por esta metodologia, o centro de qualquer projeto.

A aplicação da metodologia do Design Sistêmico prevê quatro fases. A primeira delas é a compreensão holística do território; a segunda consiste em sistematizar e analisar os sistemas produtivos existentes no território, mapeando todas as relações de produção e seus inputs e outputs, além da identificação de pontos de força, vistos como oportunidades; e pontos negativos, vistos como alavancas para a projetação de mudanças. A terceira fase é a projetação de novos fluxos e relações que estabeleçam sistemas abertos e a quarta, o confronto entre a abordagem já existente com a proposta sistêmica. Esta metodologia deve se tornar mais clara com o estudo de caso a seguir.

\section{Distrito C e Vila Flores de Porto Alegre: um workshop projetual sistêmico}

O Design Com base no relacionamento prévio estabelecido entre os programas de pósgraduação de Design da UEMG (Universidade do Estado de Minas Gerais), da UFMG (Universidade Federal de Minas Gerais), da Unisinos (Universidade do Vale do Rio dos Sinos) e Systemic Approach Foundation, e a vontade dos pesquisadores em conhecer e desenvolver novas relações 
de trabalho, foi proposta a realização de um Workshop (WS) Design Sistêmico com o intuito de aproximar os estudos dos PPG's. Esses pesquisadores, motivados pelos estudos dos Profs. Drs. Kátia Pêgo e Paulo Miranda de Oliveira, disseminadores da metodologia do Design Sistêmico do Prof. Dr. Luigi Bistagnino no Brasil, e pela influência e relação com que olham o Design Estratégico praticado no sul do país e presente nas pesquisas dos Profs. Drs. Karine Freire e Carlo Franzato, através do grupo de pesquisa para Inovação Social e Cultural do PPG em Design da Unisinos, uniram forças e estudos para levar o projeto em frente. Diante de tal motivação, propuseram aos alunos de mestrado e doutorado das Universidades (UEMG, UFMG e Unisinos) um estudo mais aprofundado da metodologia do Design Sistêmico.

Em Porto Alegre, o Workshop Design Sistêmico fez parte da disciplina Estudos Avançados em Design, na qual as primeiras aulas foram ministradas pelos Profs. Drs. Gustavo Borba e Karine Freire, da Unisinos, de forma presencial, e com a prof. Dra. Kátia Pêgo, no modo à distância. $\mathrm{O}$ objetivo era a apresentar conteúdos e conceitos aos alunos de maneira que chegassem ao trabalho coletivo com uma ideia geral dos temas a serem abordados no WS. Assim, entre os dias 28 de novembro e 01 de dezembro de 2018 aconteceu na Unisinos Porto Alegre o "WS Design Sistêmico" com a presença dos Prof. Drs. já mencionados, mais os Profs. Drs. Carlo Franzato, Paulo Miranda de Oliveira e Luigi Bistagnino.

A proposta de desenvolvimento do Workshop (WS) Design Sistêmico fomentou, inicialmente, um estudo e conhecimento do Distrito $C$ a partir de uma base metodológica sistêmica prévia estudada, que compreende o ato de projetar as relações entre pessoas, atividades e recursos de um território como uma experiência capaz de fazer evoluir na perspectiva de cultura e identidade locais, com o intuito de criar o desenvolvimento e bem-estar coletivo. (BISTAGNINO, 2011).

Importante situar que o 4을 Distrito, área em que o Distrito $C$ se localiza, foi local de grande desenvolvimento industrial a partir do início do século XX. Importantes fábricas se instalaram na região e por consequência aumentou significativamente o número de moradores e de estabelecimentos comerciais. 0 4음 Distrito era então uma zona próspera e desenvolvida da cidade, que contava com vantagens com a proximidade com o porto e uma linha férrea o que facilitava o abastecimento de matéria prima e escoamento de produção. Nos anos 1970, indústrias saem da capital e se instalam em outras regiões do estado. A diminuição da atividade industrial faz com que estabelecimentos comerciais e habitantes também abandonem a região que rapidamente se degrada. 0 4을 Distrito passa a ser uma região de baixa população, degradação arquitetônica, concentração de casas noturnas e prostituição, pouca arborização, poucas praças, alto fluxo de caminhões o baixo grau de urbanidade.

O Distrito $\mathrm{C}$, que é considerado um polo de economia criativa, economia do conhecimento e da experiência, surge como uma iniciativa para a revitalização e desenvolvimento da região por meio ideia da criação um polo criativo. Ao todo, fazem parte do Distrito $\mathrm{C}$ artistas e empreendedores que estão localizados nos bairros Floresta e São Geraldo, vista como a metade sul do chamado 40 Distrito. Mas, que também inclui partes dos bairros Independência e Moinhos de Vento, na cidade de Porto Alegre. Em 2003, foi Jorge Piqué, fundador da UrbsNova - Agência de Design Social, que ao conhecer um grupo de artistas e empreendedores que estavam instalados neste local, elaborou um projeto com o objetivo de dar visibilidade ao movimento de revitalização que começava a tomar forma ali no Distrito Criativo ou Distrito C. O potencial da região concentra-se na qualidade humana e profissional encontrada no espaço e caracteriza-se por ser um projeto de inovação social. O que move este sistema é o fortalecimento econômico dos negócios e a melhoria urbana na área onde os negócios estão estabelecidos, gerando um impacto econômico social e urbano desses artistas e empreendedores sobre um território da cidade. 
O WS Design Sistêmico foi realizado em quatro dias. No primeiro dia foram apresentados os princípios da metodologia e, principalmente, os subsídios e as bases do relevo holístico para que, por meio desse, fosse possível desenvolver a compreensão do território em estudo. 0 grupo do WS formado 15 mestrandos e doutorandos realizou uma investigação rápida no campo através de entrevistas com pessoas pertencentes ao Distrito C como: comerciantes, artistas, moradores, entre outros, e nas informações contidas nos meios digitais. Construiu-se uma visão geral sobre o Distrito $\mathrm{C}$ e as potenciais relações que existem dentro dele.

O grupo começou a trabalhar na identificação dos sistemas econômicos. Depois de uma interação, com a exaustão de determinados conceitos e discussão, surgiu a ideia de identificar os sistemas como 'produtivos', ao invés de 'econômicos'. Isso porque se sentiu a necessidade de romper com determinadas lógicas do mercado capitalista que tem forte influência sobre a forma como ainda se olha para sistemas e processos. Assim, o grande grupo dividido em 03 subgrupos começou a identificar dentro do Distrito C como se caracterizavam os sistemas produtivos: atual, criativo e colaborativo. E ainda, destinou parte do tempo para compreender que o sistema produtivo atual está centrado sob uma visão mais linear; o criativo mais na transição e o colaborativo mais numa visão sistêmica de interação. Assim, tais sistemas ainda poderiam agregar no desenvolvimento do relevo holístico.

Entre as trocas de ideias, inúmeros foram os questionamentos e dúvidas, sendo que um dos subgrupos focou o trabalho em tentar criar o relevo holístico a partir do que percebia para além das fronteiras do sistema Distrito C. Impactados pela metodologia do Design Sistêmico e talvez por estar mais em conexão ou até mais sensível à busca de uma projetação futura que resolvesse os problemas que apareciam fora dos sistema Distrito C, o subgrupo optou por construir um caminho investigando os sistemas que orbitavam o sistema em estudo.

No entendimento de que o processo é uma das fontes de riqueza do design, o subgrupo ficou motivado em estudar como seria a relação entre os moradores de rua, os comerciantes e as prostitutas do Distrito C que vivem, atuam e interagem neste espaço. No entanto, a compreensão de que esses atores não estavam em questão, uma vez que a proposta do WS Design Sistêmico era olhar, exclusivamente, para um sistema protagonista e para as relações que são estabelecidas para dentro e fora dele, e não para as relações que estabelecem com os demais sistemas igualmente relevantes. Tal entendimento só pode ser concretizado pelo grupo um dia depois de todo o trabalho já iniciado. Neste processo de saber quem é o Distrito $\mathrm{C}$ e ver como esse ecossistema atua através das múltiplas relações internas e externas é que se estabeleceu uma divergência de ideias e entendimentos.

Neste ponto surge a primeira dificuldade na transposição da metodologia do Design Sistêmico para o contexto do Distrito C. A complexidade das relações sociais que se estabeleciam na região não permitia o verdadeiro reconhecimento de um "relevo holístico" sem a inclusão de elementos que claramente faziam parte do sistema, embora não fossem os agentes diretos das atividades econômicas/produtivas que caracterizavam o Distrito C. Evidenciaram-se nas entrevistas e observações em campo, a existência de relações fortes e orgânicas entre indivíduos supostamente externos ao sistema com aqueles que eram considerados parte do sistema. Um dos subgrupos do WS considerou que excluir do relevo holístico, e do sistema, pessoas como as profissionais do sexo e moradores de rua parecia estabelecer um corte tão arbitrário quanto artificial na paisagem social. Se por um lado este corte facilitava a delimitação do escopo do projeto que se pretendia executar, por outro, ia na contramão da proposta sistêmica e humanista do Design Sistêmico. Ficava evidente que além de lidar com a realidade de maneira sistêmica, havia a urgência de uma discussão que abraçasse a complexidade com que as relações se estabeleciam neste território. O relevo holístico não deveria ser, aos olhos deste subgrupo, um retrato estático da situação encontrada, mas uma representação de relações sistêmicas e 
complexas que estavam em constante, e muitas vezes imprevisível, movimento.

A metodologia do design sistêmico, da forma como estava sendo operada no WS, não parecia dar espaço suficiente para abordagem ampla e sistêmica da situação posta no Distrito C. Esta poderia ser uma excelente oportunidade de tensionar a metodologia buscado caminhos operacionais e experimentando a mobilidade possível no contexto do Design Sistêmico. Entretanto, diante deste impasse, surgiu como meio de resolver a querela, não uma adaptação da metodologia à realidade, mas uma adaptação da realidade à metodologia.

Assim, ao longo do processo de troca de informações, divergências, entendimento da metodologia do design sistêmico, tanto por parte dos participantes quanto por parte dos mestres, acabou se estabelecendo um outro objeto de estudo, mais fechado enquanto sistema e paradigmático enquanto case expressivo de economia criativa, isto é, que agrega inúmeros negócios que tem por ponto comum a inovação social. Para que o grupo pudesse testar e compreender de fato as bases da teoria, a nova proposta de trabalho ficou centrada no Vila Flores, ao invés de dar continuidade ao estudo do Distrito $C$.

O Vila Flores é um espaço que agrega arte, cultura, educação e negócios voltados à inovação social e sustentabilidade. Localiza-se na rua São Carlos esquina com a rua Hoffmann, no bairro Floresta, em Porto Alegre. O prédio do Vila Flores é um complexo arquitetônico formado por 3 edificações e um pátio em um terreno interno. As edificações estão listadas como patrimônio cultural da cidade e abrigam diversas funções: local para a realização de atividades socioculturais, que são coordenadas pela Associação Cultural Vila Flores, espaço de trabalho de artistas e empreendedores criativos e ambiente de aprendizado.

Ou seja, por ser um ambiente conhecido e de domínio do grupo de estudo do Design Sistêmico, a prática redirecionou o objeto de pesquisa para que fosse possível aplicar a metodologia. Assim, foi feito um novo relevo holístico, que teve como ponto de partida a identificação dos sistemas produtivos atual, criativo e colaborativo do Vila Flores, originando uma nuvem de palavras que compuseram o que há neste sistema.

Figura 1 - Sistema Produtivo Atual, Criativo e Colaborativo

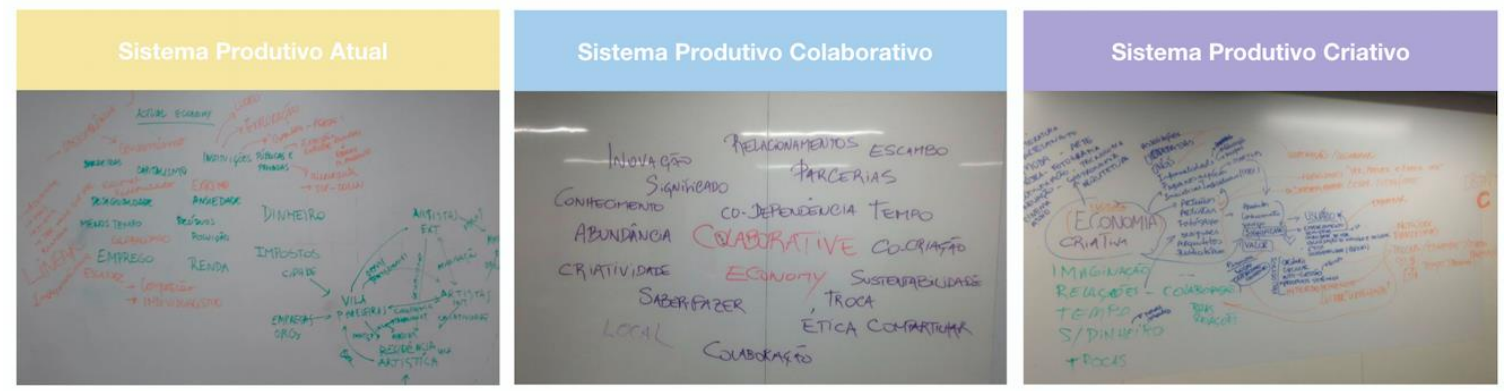

Fonte: “Adaptado do projeto de apresentação final do WS Design Sistêmico”, dezembro 2018

Em seguida, foram identificadas e classificadas as inúmeras e diversas atividades do espaço dentro desta dimensão do Sistema Produtivo Vila Flores, quais as atividades que se caracterizam de forma linear, de transição ou sistêmica, assim forma caracterizados tries diferentes sistemas: sistema produtivo atual, sistema produtivo colaborativo e sistêmica (atual, criativa e colaborativa). 
Figura 2 - Identificação Sistema Produtivo Vila Flores.
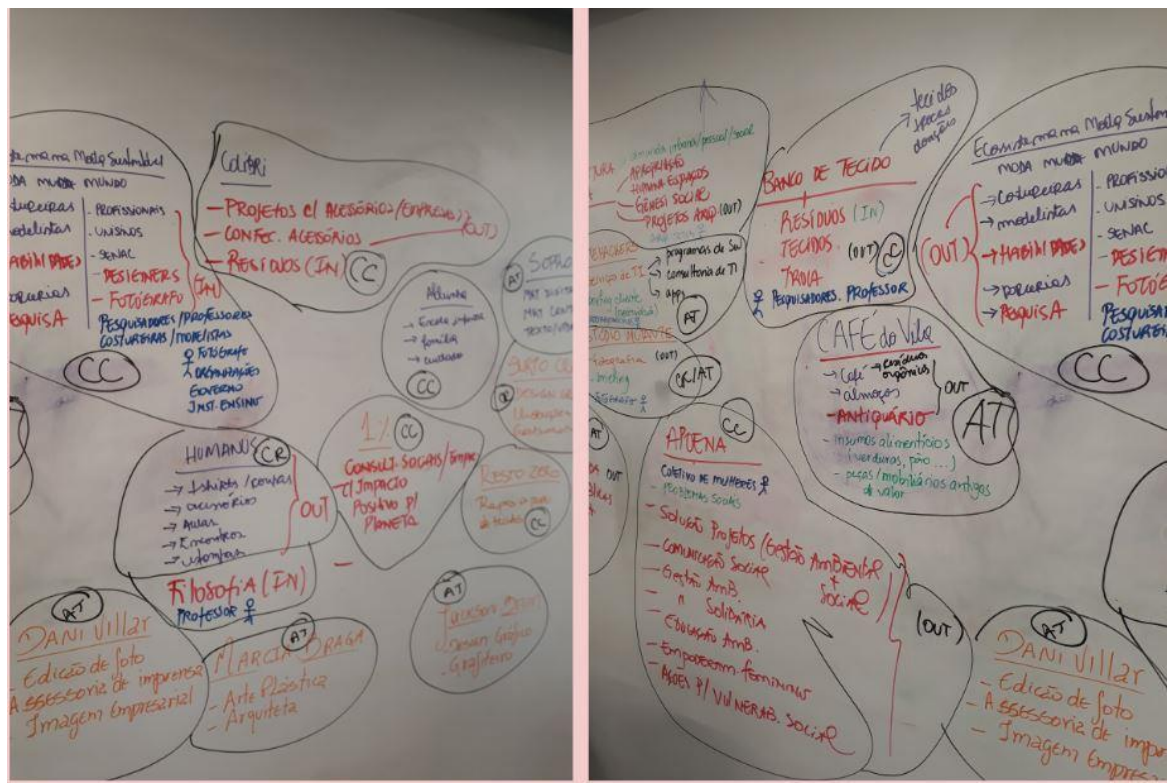

Fonte: “Adaptado do projeto de apresentação final do WS Design Sistêmico", dezembro 2018.

Depois foram analisadas as relações entre os 'vileiros' com os principais sistemas deste sistema, as relações internas e as relações com outros sistemas. O WS Design Sistêmico concentrou-se nesta esfera apenas, não abrindo espaço para uma possível projetação ou ainda um aprofundamento do estudo dos sistemas externos ao sistema Vila Flores.

Figura 3 - Análise relações dos Vileiros no Vila Flores

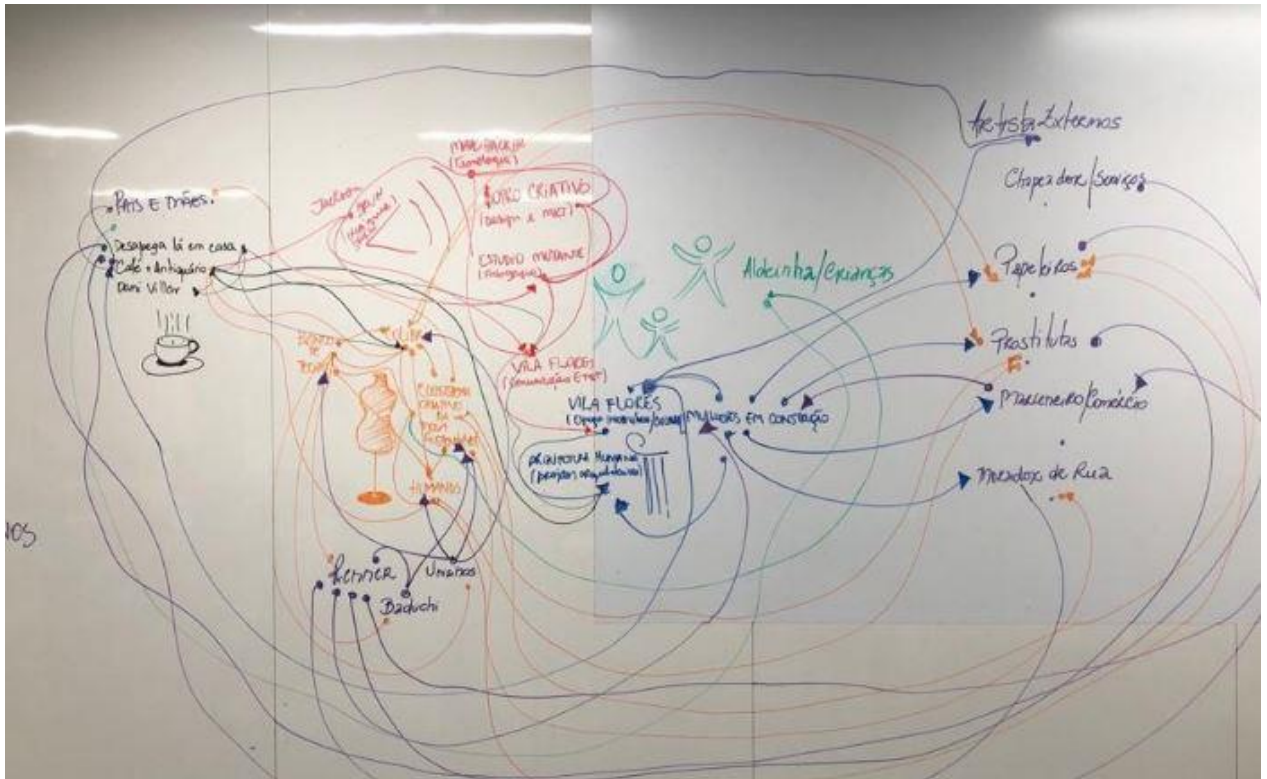

Fonte: “Adaptado do projeto de apresentação final do WS Design Sistêmico”, dezembro 2018. 


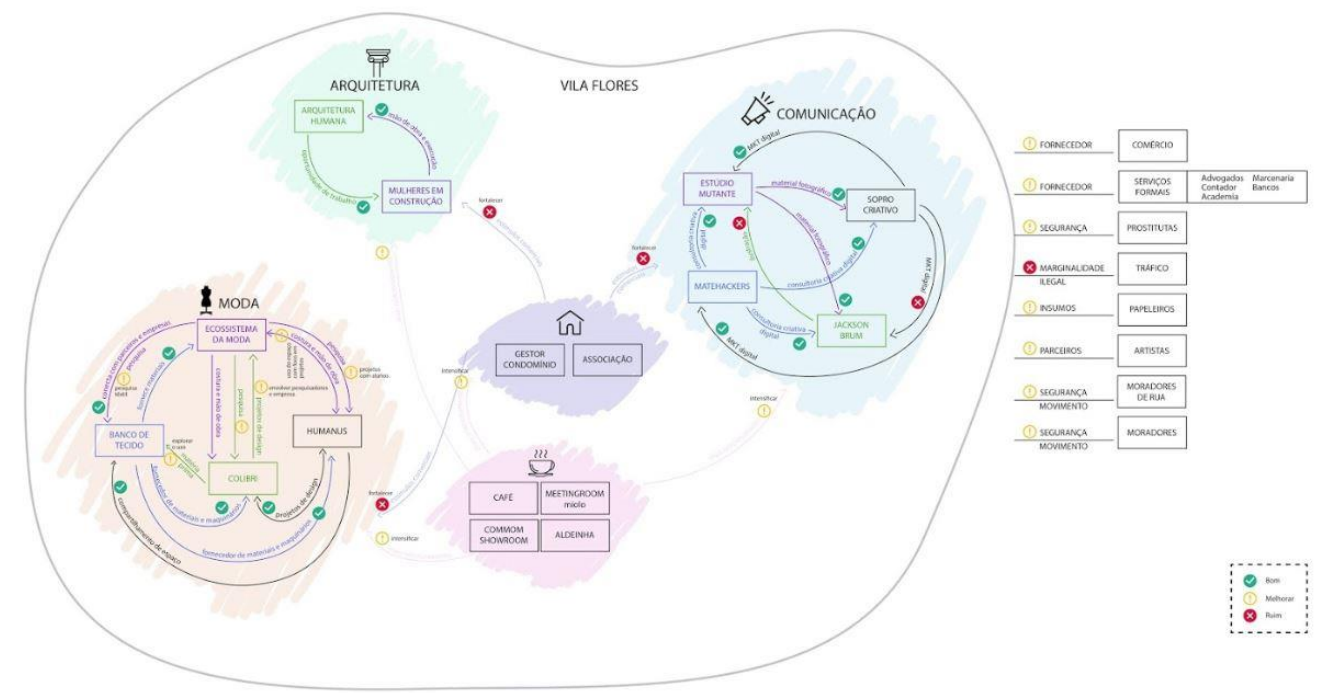

Fonte: “Adaptado do projeto de apresentação final do WS Design Sistêmico”, dezembro 2018.

\section{Distrito C e Vila Flores de Porto Alegre: um workshop projetual sistêmico}

Consoante com seu horizonte de emergência histórica e explicitamente crítico, e aqui, lê-se crítico em duplo sentido, tanto de situação de crise quanto de retomada contínua da possibilidade crítica, admite-se que seja bem aventurado todo questionamento coerente com a proposta do Design Sistêmico, afinal, é próprio à autopoiese dos saberes empíricos a explicitação de seus limites e o vislumbre de seu ulterior aperfeiçoamento. A intenção desse movimento não é de vigilância epistemológica, pois a condição negativa dada à polícia filosófico-científica, reduzindo o trabalho crítico da transcendentalidade a um mero tribunal das racionalidades, tendo no lugar do juiz o logos e no lugar do réu, a realidade sensível, é incoerente com as demandas projetuais às quais se torna viável todo o design (incluindo aí também o sistêmico). A intencionalidade crítica desta perspectiva sobre a teoria e o método do Design Sistêmico é a contínua construção de modos de pesquisa e ação projetual capazes de atuar eficazmente no contexto crítico destacado pelo próprio Design Sistêmico. E aqui entende-se a eficácia a partir do compromisso ontológico de interventividade prática e poética de todo projeto, de todo design com a realidade, com mundos em construção (BUCHANAN, 2017).

A possibilidade dessa abordagem crítica se efetiva, principalmente, quando o Design Sistêmico se propõe não simplesmente como um modo de saber, mas como um modo de agir e, sobretudo, de viver, como uma forma de viver em contextos críticos com vistas à sustentabilidade. Capra, uma das vozes mais importantes na articulação de um pensamento sistêmico, retoma em seu discurso a palavra sustentabilidade com inúmeras ressalvas, que quase quarenta anos depois de sua emergência, faz sentido serem afirmadas: 
“Desde a sua introdução nos primeiros anos da década de 1980, o conceito de sustentabilidade é continuamente distorcido, abusado e até banalizado, enquanto sua utilização se faz sem referimentos ao contexto ecológico que deu a ele seu correto significado. Penso então que se merece refletir um instante sobre o real significado de 'sustentabilidade'. Aquilo que em uma sociedade sustentável se torna o 'sustento', não são tanto o crescimento econômico, o desenvolvimento e o lucro competitivo, quando frequentemente a inteira rede da vida da qual depende a nossa sobrevivência a longo tempo. Em outras palavras, uma comunidade é projetada de maneira tal pela qual as suas próprias modalidades de vida, as suas tecnologias e as suas instituições sociais suportem e cooperem com a intrínseca habilidade da natureza de sustentar a vida. O primeiro passo por dar, naturalmente, é aquele de compreender os princípios de organização que o ecossistema desenvolveu ao fim de sustentar a rede da vida. Esta compreensão é aquela que eu defini 'tornar letrados sobre o plano ecológico'. Nas próximas décadas, a sobrevivência da humanidade dependerá deste tipo de compreensão e, consequentemente, os dos de viver com ela" (CAPRA, 2011: 209, tradução nossa) ${ }^{2}$

Percebe-se um profundo alinhamento de Capra com Bistagnino, mas o ponto de deslocamento da centralidade econômica para um eixo humano em Bistagnino, não se manifesta em Capra, posto que, para ele, como fica evidente no parágrafo acima, a humanidade só garantirá sua sobrevivência quando se tornar ecológica. Por isso, Capra não prefere centralizar o humano diante da realidade múltipla das redes da vida. O próprio conceito de rede não prevê centralizações, mas, se elas persistirem por aglomerações e globalizações necessárias, que sejam em prol da vida, e não somente da vida humana, pois ela, exclusivamente, não é viável. A questão em si, parece não ser de desprestígio do humano, mas de uma análise transversal das relações ecossistêmicas vitais, de um vitalismo que não hierarquize um feixe de relações em detrimento de outras. Obviamente, Capra, ao falar de redes de vida, já está falando de sistemas complexos, abertos, autopoieticamente gerados e organizados, privilegiando-os sobre os sistemas simples, fechados, incapazes de se autogerir e regenerar, basicamente porque estes sistemas não são vivos. Portanto, o primeiro questionamento a ser feito ao Design Sistêmico é sobre a centralidade no humano. Mesmo com o cuidado que este centramento não seja discursivamente um velho antropocentrismo, como afirmam Bistagnino e Celaschi (2008), reconhecendo que foi o próprio humanismo uma das causas da situação crítica pela qual o Design Sistêmico surge como antagonista, talvez essas ressalvas não bastem para dar conta da perspectiva ecológica solicitada por Capra. Isto porque a robustez do discurso teórico-metodológico do Design Sistêmico somente se efetiva caso seja coerente como princípio de práticas projetuais adequadas a um marco teórico mais amplo, isto é, de acordo com um paradigma ecológico.

Este questionamento de natureza epistemológica remete a um cerne axiológico: para ser coerente com a perspectiva sustentável defendida por Capra, ele solicita a vida como valor máximo e inegociável, a vida em sua diversidade, em suas mais variadas formas, tudo isso para garantir a própria sobrevivência humana. Talvez haja um centramento humanístico implícito no

\footnotetext{
2 "Sin dalla sua introduzione nei primi anni ' 80 , il concetto di sostenibilità è spesso distorto, abusato e persino banalizzato in quanto utilizzato senza riferimenti al contesto ecologico che ad esso darebbe il corretto significato. Penso quindi che meriti riflettere un istante sul reale significato di `sostenibilità`. Ció che in una società sostenibile viene 'sostenuto', non sono tanto la crescita economica, lo sviluppo o il profitto competitivo, quando piuttosto l'intera rete della vita (web of life) dalla quale dipende la nostra sopravvivenza a lungo termine. In altre parole, una comunità è progettata in maniera tale per cui le sue stesse modalità vitali, le tecnologie e le istituzioni sociali supportino e cooperino con l'intrinseca abilità della natura nel sostenere la vita. Il primo passo da compiere, naturalmente, è quello di capire i principi di organizzazione che l'ecosistema ha sviluppato ai fini di sostenere a rete della vita. Questa comprensione è quella che io definisco `diventare letterati sul piano ecologico` ('ecological literacy`). Nelle decadi a venire la sopravvivenza dell'umanità dipenderà da questo tipo di comprensione, cioè dalla nostra capacità i principi di base dell'ecologia e, di conseguenza, i modi di vivere con essa." (CAPRA, 2011: 209).
} 
discurso de Capra, pois ele nunca chega a cogitar a possibilidade de uma posteridade com o fim da vida humana, seja por fatalidade ou por mera transformação em outra vida que não humana. Mas também não assume com o humano nenhuma diretriz monárquica sobre o privilégio das redes da vida. Com ele, evidencia-se a interdependência absoluta entre vida e humano, portanto, para não reduzir vida a humano, já que todo humano é vida, talvez seja necessário levar em conta que há vida para além do humano, de que o humano seja um momento da vida. Sendo assim, aconselhase para o Design Sistêmico um centramento em relação às redes da vida, isto também para melhor compreender o próprio humano e sua forma de vida complexa.

O pensamento ecológico de Capra sobre o componente humano das redes da vida se endereça para um problema fundamental das teorias sistêmicas que ficaram evidentes no workshop de Design Sistêmico: quais princípios projetuais das nossas futuras instituições sociais deverão ser coerentes com os princípios de organização que a natureza desenvolveu para sustentar as redes da vida?" (CAPRA, 2011: 213).

Como Bistagnino e Celaschi (2008), Capra retoma o exemplo de Leonardo da Vinci como um tipo paradigmático para estudos científicos e projetuais ecológicos, dele pontuando a inseparabilidade entre arte e ciência, entre desenhos e diagramas como formas de mapeamento, de produção de conhecimento qualitativo e intervenção na realidade. Os diagramas de Leonardo da Vinci são tanto uma expressão artística espiritual materializada em obras quanto conhecimento científico sobre a matéria, nele a dicotomia entre materialismo e linguagem se dissolve. Com Leonardo, o químico e o sociólogo se encontram num momento precedente à grande cisão moderna dos saberes. Poderia ser até dito que Leonardo é um marco histórico para o pensamento ecológico de Capra.

A expressão visual das práticas de mapeamento de sistemas e o pensamento diagramático do Design Sistêmico comungam dessa aproximação com o método científico qualitativo de da Vinci, no entanto, insinuam uma herança mecanicista- materialista reificante quando não conseguem lidar com o dinamismo da hiperfluidez das significações produzidas nas redes culturais, com o acontecimento do sentido que se expressa pelo corpo de tais redes. Seja na semiosfera ou na noosfera, a matéria ganha características tais que o materialismo mecanicista, em si, não consegue dar conta, o que solicita abordagens não complementares ou coadjuvantes, mas tão necessárias e importantes quanto o são os diagramas de causa-e-efeito da matriz materialista do Design Sistêmico, o que não significa renunciar ao materialismo como um todo. Portanto, perspectivas mais voltadas à semiótica e à linguística devem auxiliar as tarefas do Design Sistêmico em mapear e intervir em ecossistemas humanos. No entanto, não perder a sua perspectiva materialista é fundamental, inicialmente, para não cair nas tentações de uma metafísica dos signos, e, principalmente, para dar conta das dinâmicas dos ciclos de matéria e energia das forças vitais que garantem a robustez da perspectiva ecológica como produtora de conhecimento interventivo e responsável sobre a realidade.

Nesse sentido, o desdobramento da perspectiva ecológica de Guattari (2001) em três ecologias - ecologia material, ecologia social e ecologia da subjetividade - dentro de um paradigma ético-estético instrumentalizado pela cartografia de signos (GUATTARI, 2006), surge inicialmente como uma possível chave de leitura para os problemas ecossistêmicos os quais enfrenta o Design Sistêmico, não só para garantir modos de operacionalização metodológica, mas, prioritariamente, a possibilidade de sua própria autocrítica e regeneração. Pois, principalmente no workshop, aquilo que por vezes fica implícito no discurso teórico, explicita-se no encontro das subjetividades projetuais, isto é, os dissensos procedimentais agonísticos entre as múltiplas perspectivas participantes, tornando-os dependentes de tomadas de decisão duras e verticalizadas incoerentes com o processo coletivo e participativo, contrariando as possibilidades de uma abordagem ecológica pluralista mais ampla e transversal. Sendo mais explícito, a 
insistente tentativa dos participantes do workshop em tomar o caso Vila Flores na sua própria constituição ontológica viva de sistema dinâmico e aberto era constantemente perseguida, cooptada e direcionada para a operacionalidade mais mecânica dos sistemas fechados, comprometendo o devir não só do caso analisado, como do próprio método em questão.

Sem sair do âmbito do design italiano, a complexidade do componente humano junto aos problemas projetuais de ordem ecológica é tão específica que, a partir de uma perspectiva epistemológica similar, o design estratégico de Manzini (2016) vem se preocupando cada vez menos com a estrita materialidade dos parâmetros de mensuração de impacto ambiental para atentar cada vez mais às possibilidades de organização coletiva dos sujeitos projetantes mediados por culturas de projeto focadas em inovação social, oferecendo outras ferramentas projetuais como o design de cenários e abordagens dialógicas fundamentadas na cocriação.

Estas outras possibilidades estão longe de oferecerem um ponto final qualquer às questões levantadas, pelo contrário, devem servir de insumo para o enriquecimento das respostas, estas, sempre momentâneas e coerentes com a fragilidade dos contextos analisados e com a parcialidade das perspectivas interessadas.

\section{Conclusão}

A reflexão crítica apresentada neste artigo centrou-se em alguns pontos relevantes da teoria e do método do Design Sistêmico do professor italiano Luigi Bistagnino. Com base na experiência do workshop projetual que transitou entre o estudo de caso do Distrito $C$ e que, ao longo do processo, acabou direcionado para o estudo de caso aplicado sobre o ecossistema criativo Vila Flores de Porto Alegre, pode-se inferir algumas inconsistências e insuficiências metodológicas do Design Sistêmico, relativamente distante na tentativa de dar conta da complexidade do componente humano. Entende-se que o componente humano, em toda sua complexidade simbólica, afetiva, subjetiva, linguística presente e atuante em sistemas sociais abertos, é essencial à compreensão das dinâmicas dos sistemas naturais às quais participa, influenciando de forma direta os ciclos de energia e matéria por meio da produção e circulação de produtos materiais e imateriais que hoje se tornam a expressão de um planeta em degradação. Portanto, as abordagens projetuais devem tentar dar conta de toda essa dimensão humana, sem reduzir em nada a sua complexidade. O Design Sistêmico é uma das inúmeras possibilidades de se efetivar essas abordagens, feliz na sua intencionalidade, robusto na sua forma de pensar diagramática, mas frágil quanto à transposição dos princípios éticos e estéticos da perspectiva ecológica à operacionalidade projetual.

Nesse sentido, sobre a aplicação da metodologia no Vila Flores, percebe-se a necessidade de estudos futuros que vislumbrem os feixes de relações que se estabelecem fora e dentro do sistema Vila Flores com os demais sistemas que interagem ou não com ele. A riqueza das relações humanas que estão para além dos produtos e serviços identificados no relevo holístico do design sistêmico oferecem um vasto campo de estudo e de trocas possíveis que fomentem ainda mais estas relações e que possam servir de inputs para desenvolver novas possibilidades dentro do sistema.

\section{Referências}

BERTALANFFY, Ludwig Von. Teoria geral dos sistemas: Fundamentos, desenvolvimento e aplicações. Tradução de Francisco M. Guimarães. Petrópolis: Vozes, 2012. 360 p. Título original: General system theory: foundations, development, applications. ISBN: 978-85- 326-3690-4. 
BISTAGNINO, Luigi; CELASCHI, Flaviano; GERMARK, Claudio. Uomo al centro del progetto: design per um nuovo umanesimo. Torino: Allemandi \& C, 2008. 172 p. ISBN: 978-88-422-1629-2. Disponível em: <http://www.systemicfoundation.org/books/>.

BISTAGNINO, Luigi. Il guscio esterno visto dall'interno. Milano: Casa Editrice Ambrosiana, 2008. 248 p. ISBN: 978-88-08-18422-1. Disponível em: <http://www.systemicfoundation.org/books/>.

BISTAGNINO, Luigi. Design sistêmico: Progettare la sostenibilità produttiva e ambientale. Bra: Slow Food, 2011. 310 p. ISBN: 978-88-849-9270-3.

BISTAGNINO, Luigi. Design sistêmico: uma abordagem interdisciplinar para a inovação. In: Moraes; Dias; Krucken (Org.). Cadernos de Estudos Avançados em Design: sustentabilidade II. 2. ed. Belo Horizonte: EdUEMG, 2016 p. 13-29. ISBN: 978- 85-62578- 35-9.

BUCHANAN, R. Mundos em construção: design [projeto], gerenciamento e a reforma da cultura organizacional. Arcos Design. Rio de Janeiro, V. 9 N. 2, Dezembro, 2017, pp. 1-30.

CAPRA, Fritjjof. A ciência de Leonardo da Vinci: um mergulho profundo na mente do grande gênio da Renascença. Sao Paulo: Cultrix, 2008. 368 p. ISBN: 978-85-316- 1003-5.

CAPRA, Fritjjof. A teia da vida: uma compreensão científica dos sistemas. São Paulo: Cultrix, 2012. 256 p. ISBN: 978-85-316-0556-7.

CAPRA, Fritjof. Una scienza per il vivere sostenibile. In: BISTAGNINO, Luigi. Design sistêmico: Progettare la sostenibilità produttiva e ambientale. Bra: Slow Food, 2011. 310 p.

CAPRA, Fritjjof; LUISI, Pier Luigi. A visão sistêmica da vida: uma concepção unificada e suas implicações filosóficas, políticas, sociais e econômicas. São Paulo: Cultrix, 2014. 615 p. ISBN: 97885-316-1291-6.

GUATTARI, Félix. As três ecologias. 10.ed. Campinas: Papirus, 2001.

GUATTARI, F. Caosmose. Um Novo Paradigma Estético. Ed. 34. São Paulo, 2006. KRUCKEN, Lia. Design e território: valorização de identidades e produtos locais. São Paulo: Studio Nobel, 2009. 126 p. ISBN: 978-85-213-1496-7.

MANZINI, E. Design Culture and Dialogic Design. Design Issues: Volume 32, Number 1, MIT: 2016.

MIRANDA, Paulo; PÊGO, Kátia Andréa Carvalhaes. Reconhecimento do território através do método do design sistêmico de mapeamento geiconográfico. In: KRUCKEN, LIA; MOL, ANDRÉ; LUZ, DANIELA (Org.). Territórios criativos: design para valorização da cultura gastronômica e artesanal. 1. ed. (eletrônica). Belo Horizonte: Atafona, 2017. cap. 13, p. 193-206. ISBN: 978-85931-9400-9. Disponível em: <https://www.editoraatafona.net>.

MORAES, Dijon; KRUCKEN, Lia (Org.). Cadernos d e estudos avançados em design: sustentabilidade I. Barbacena: EdUEMG, 2009. 108 p. ISBN: 978-85-62578-00-7.

MORAES, Dijon; KRUCKEN, Lia (Org.). Cadernos de estudos avançados em design: sustentabilidade II. 2. ed. Belo Horizonte: EdUEMG, 2016. 152 p. ISBN: 978-85-62578- 35-9.

MORIN, Edgar. Introdução ao pensamento complexo. 5. ed. Porto Alegre: Sulina, 2015. 120 p. ISBN: 978-85-205-0598-4. 